\title{
Pyrolysis Gas Chromatographic Evaluation of Sequence Distributions in Acrylate-Methacrylate Copolymers
}

\author{
Shigehiko YAmaguchI, Jiro HIRANO, and Yoshihiro ISODA \\ Nippon Oil \& Fats Co., Ltd., Tsukuba Research Laboratory, \\ Tokodai 5-10, Toyosato-machi, Ibaraki 300-26, Japan
}

(Received March 14, 1985)

\begin{abstract}
Sequence distributions of acrylate-methacrylate copolymers were evaluated with Yamaguchi-Yokoyama's pyrogram. The diad concentration ratio of $\mathrm{P}_{2}$ (acrylate-acrylate) to $\mathrm{P}_{2}$ (acrylate-methacrylate) was empirically estimated by the peak area ratio of related acrylate monomer to dimer. Sequence distributions of diad in the ethyl acrylate (EA)-butyl methacrylate (BMA) copolymer, synthesized under different conditions, were comparatively evaluated. Their sequence distributions were also possible to evaluate by the peak area ratio of EA-EA dimer to EA-BMA dimer on their pyrogram. The results from the former method were in good agreement with those from the latter method. Furthermore, the method principally the same as the former was applied to evaluate the diad concentration ratios in EA-butyl acrylate (BA)-BMA terpolymers.

KEY WORDS Pyrolysis Gas Chromatography / Sequence Distribution / Acrylate-Methacrylate Copolymer / Curie Point Pyrolyzer /
\end{abstract}

Pyrolysis gas chromatography has been frequently utilized not only for the qualitative and compositional analysis but also for the evaluation of the sequence distributions of copolymers. ${ }^{1-4}$ Recently, the authors described a method for determining the compositions of acrylic multi-component polymers by using the characteristic peak area ratio on their pyrograms. ${ }^{5}$ As the peak area ratios for acrylates to methacrylates were not precisely equal to the ratio of their monomer units in the copolymers, correlation factors between these ratios were obtained empirically.

In this work, the sequence distributions of acrylate-methacrylate copolymers were studied by using the peak area ratio of the related acrylate monomer to dimer as described in the previous paper. The ratio should vary with the sequence distribution of acrylate and methacrylate units, e.g., the diad concentration ratio of $\mathrm{P}_{2}$ (acrylate-acrylate) to $\mathrm{P}_{2}$ (acrylate-methacrylate). Although the sequence distributions of acrylic copolymers have been, to a great extent, studied by NMR, ${ }^{6}$ by the proposed method those of multi-component copolymers can be estimated more easily.

\section{EXPERIMENTAL}

\section{Samples}

The copolymer samples were synthesized by the radical polymerization in a flask equipped with a stirrer, a nitrogen inlet, and an initiator inlet tube. Polymerization was carried out always using a monomer mixture $(78.4 \mathrm{~g})$ in the presence of xylene $(120.0 \mathrm{~g})$ and $t$-butyl peroxyisopropyl carbonate $(1.6 \mathrm{~g}$, Nippon Oil \& Fat Co.) as a radical initiator, at $120^{\circ} \mathrm{C}$ under a nitrogen gas atmosphere. The initiator dissolved in xylene $(40.0 \mathrm{~g})$ was slowly added to the monomer mixture with xylene $(80.0 \mathrm{~g})$ over $1 \mathrm{~h}$, and the polymerization was discontinued after an additional $3 \mathrm{~h}$. By this method, EA(ethyl acrylate)-BMA (butyl methacrylate) copolymers (EA/BMA mole ratio= 
$9 / 1,8 / 2,7 / 3,6 / 4,5 / 5,4 / 6,3 / 7,2 / 8$ and $1 / 9)$, EA-EMA (ethyl acrylate) copolymers (EA/ EMA mole ratio $=8 / 2,6 / 4,4 / 6$, and $2 / 8$ ), BA (butyl acrylate)-MMA (methyl methacrylate) copolymers (BA/MMA mole ratio= $8 / 2,6 / 4,4 / 6$, and $2 / 8$ ) and a EA-BA-BMA terpolymer $(\mathrm{EA} / \mathrm{BA} / \mathrm{BMA}$ mole ratio $=3 / 3 / 4)$ were obtained. Other polymer series of EA-BMA copolymers (EA/BMA mole ratio= $5 / 5$, the time of $\mathrm{EA}$ addition $=5,10$ and $20 \mathrm{~min})$ and a EA-BA-BMA terpolymer (EA/BA/BMA mole ratio $=3 / 3 / 4$, the time of $\mathrm{BA}$ addition $=15 \mathrm{~min}$ ) which have different sequence distributions, were also obtained by adding the initiator plus one comonomer solution to the other monomer solution. The composition of the samples was calculated from the monomer feeds by measuring the residual monomers by gas chromatography, and thus the conversion yield proved to be almost $100 \%$ as for each sample.

\section{Conditions of Pyrolysis Gas Chromatography}

An induction heating pyrolyzer (Curie-point pyrolyzer; Japan Analytical Industry, Model JHP-2) was attached to a gas chromatograph (Hitachi, Model 163). An aliquot of the solution of samples (the amount of polymer was less than $0.1 \mathrm{mg}$ ) was deposited on a piece of foil, whose curie temperature was $590^{\circ} \mathrm{C}$, and after removing the solvent, the foils coated with samples were used for the following procedure. Then the sample was pyrolyzed at

Table I. Gas chromatographic conditions

\begin{tabular}{ll}
\hline \multicolumn{1}{c}{ Conditions } & Pyrogram \\
\hline $\begin{array}{l}\text { Glass column }(2 \mathrm{~m} \times 3 \mathrm{~mm} \text { i.d.) packed with } \\
10 \% \text { Thermon-3000 on Chromosorb W }\end{array}$ & Figure 3 \\
$(60-80 \mathrm{mesh})$. & \\
Programmed from 50 to $220^{\circ} \mathrm{C}$ at $5 \mathrm{~K} \mathrm{~min}^{-1}$ & \\
\hline $\begin{array}{l}\text { Glass column }(2 \mathrm{~m} \times 3 \mathrm{~mm} \text { i.d. }) \text { packed with } \\
10 \% \text { Silar } 10^{\circ} \mathrm{C} \text { on } \mathrm{Gaschrom} \mathrm{Q} \\
(100-120 \mathrm{mesh}) .\end{array}$ & Figure 5 \\
Programmed from 50 to $220^{\circ} \mathrm{C}$ at $5 \mathrm{~K} \mathrm{~min}^{-1}$ & \\
\hline
\end{tabular}

$590{ }^{\circ} \mathrm{C}$ under a flow of nitrogen carrier gas. A glass column packed with Thermon-3000 or Silar-10 C was used. The conditions of gas chromatography are summarized in Table I. The peak areas were measured by an integrator (Shimadzu, Chromatopac CR1A). Identification of the peak was carried out by a pyrolysis-gas chromatograph-mass spectrometer system (JEOL, JMS-D300).

\section{RESULTS AND DISCUSSION}

\section{Evaluation of Sequence Distributions Using Peak Area Ratio of Acrylate Monomer to Dimer}

It has been reported that the thermal degradation of acrylate-methacrylate copolymers changes with the sequence distributions of their associated monomer units. ${ }^{4,5,7}$ Figure 1 summarizes the variation of the relative yields of the monomer to dimer from a copolymer and a homopolymer mixture. With the increase of the hybrid diad $\mathrm{P}_{2}$ (acrylatemethacrylate) in the polymer, the yield of the acrylate monomer increased while that of the acrylate dimer decreased. Therefore, the ratio of acrylate monomer to dimer yields might be a good measure for the sequence distributions.

In this work, EA-BMA copolymers as mentioned above, were studied to investigate the relationship between the ratio of monomer to dimer and the sequence distributions. Figure 2 shows the relationship of the ratio of monomer to dimer and the theoretical ratio of diad concentrations $\mathrm{P}_{2}(\mathrm{EA}-\mathrm{EA})$ to $\mathrm{P}_{2}(\mathrm{EA}-\mathrm{BMA})$ in the EA-BMA copolymers. The theoretical diad concentrations were calculated by assuming that the copolymerization proceeded according to the Mayo-Lewis equation in every $1 \mathrm{~mol} \%$ conversion of the polymerization process. The monomer reactivity ratios were calculated from the following $Q$ and $e$ values $^{8}$ for EA and BMA: 0.42 and 0.62; 0.67 and 0.43 ; respectively. The hybrid concentration $\mathrm{P}_{2}$ (EA-BMA) was estimated by the following relations: $\quad \mathrm{P}_{2}(\mathrm{EA}-\mathrm{EA})+\mathrm{P}_{2}(\mathrm{BMA}-\mathrm{BMA})+$ 
Pyrolysis Gas Chrolıatographic Evaluation

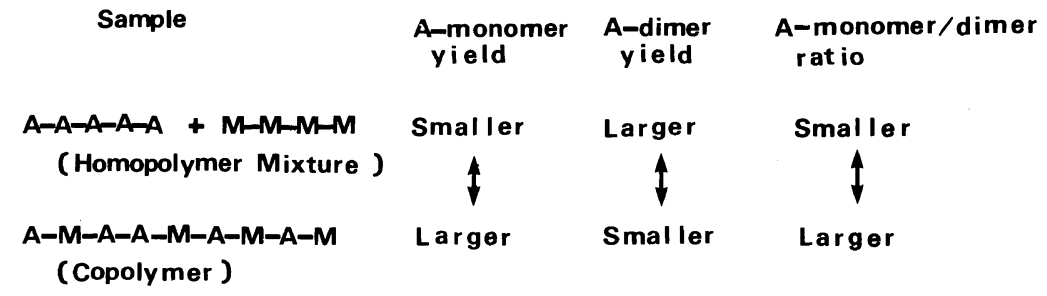

\section{A : Acrylate $\quad M$ : Methacrylate}

Figure 1. Variation of acrylate monomer/dimer ratio in pyrolytic products with sequence distributions.

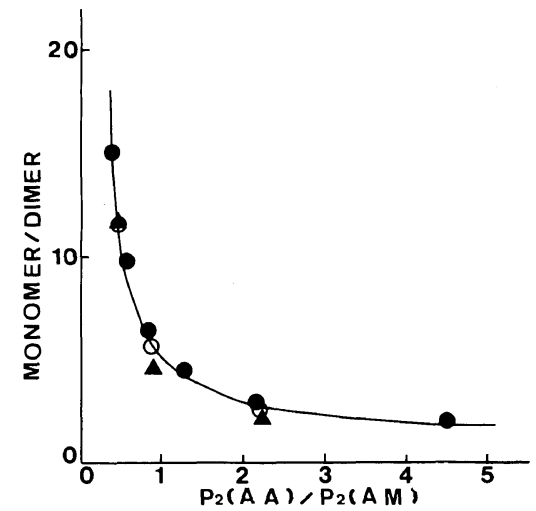

Figure 2. Relationship between the ratio of related acrylate monomer/dimer in pyrolytic products and the diad concentration ratio of $\mathrm{P}_{2}$ (acrylate-acrylate) $/ \mathrm{P}_{2}$ (acrylate-methacrylate): $A$, acrylate; $M$, methacrylate. Samples: ○, EA-BMA; O, EA-EMA; $\triangle$, BA-MMA copolymer.

$\mathrm{P}_{2}(\mathrm{EA}-\mathrm{BMA})=1$.

From the relationship shown in Figure 2, the diad concentration ratio $\mathrm{P}_{2}$ (acrylateacrylate) to $P_{2}$ (acrylate-methacrylate) can be easily estimated by the acrylate peak area ratio of monomer to dimer. In practice, the results obtained in the cases of EA-EMA copolymers and BA-MMA copolymers showed good agreement with those of EA-BMA copolymers as shown in Figure 2 ( $Q$ and $e$ values for EMA, BA and MMA: 0.70 and $0.44 ; 0.43$ and $0.53 ; 0.74$ and 0.40 ).

In six repeated measurements of the monomer/dimer ratio, the standard deviations and the coefficients of variation were 0.33 and $2.38 \%$ for an EA-BME copolymer (EA/
$\mathrm{BMA}=4 / 6$ ), and 0.15 and $5.89 \%$ for another copolymer $(\mathrm{EA} / \mathrm{BMA}=8 / 2)$.

\section{Evaluation on Sequence Distributions Using Peak Area Ratio of Dimers}

From the relationships shown in Figure 2, the sequence distributions can be estimated using the monomer/dimer ratio. To validate this method (Method 1), we investigated the diad concentrations by another method using other peak area ratios.

Figure 3 shows the pyrogram of an EA-BMA copolymer. EA-BMA hybrid dimer peaks are observed besides those for the EA-EA dimer. The relation of the ratio of dimer peak area EA-EA/EA-BMA and the ratio of diad concentration $\mathrm{P}_{2}(\mathrm{EA}-\mathrm{EA}) /$ $\mathrm{P}_{2}(\mathrm{EA}-\mathrm{BMA})$ is shown in Figure 4. The plot gives a fairly good straight line $(r=0.67)$. The diad concentrations can thus be estimated using the dimer ratio (Method 2). In six repeated measurements, the standard deviation of the dimer ratio and the coefficients of variation were 0.03 and $5.13 \%$ for the former EA-BMA copolymer $(\mathrm{EA} / \mathrm{BM}=4 / 6)$, and 0.14 and $4.11 \%$ for the latter one (EA/ BMA $=8 / 2$ ), respectively.

To evaluate applicability of Method 1 , the analytical results are compared with those from the Method 2. For this comparison, the copolymer samples are synthesized by adding EA monomer plus an initiator to BMA monomer, to obtain the copolymer of EA/ BMA ratio of $5 / 5$ in mole ratio. In this po- 
Table II. Analytical diad concentrations of samples $(\mathrm{EA} / \mathrm{BMA}=5 / 5)$

\begin{tabular}{|c|c|c|c|c|c|c|c|c|}
\hline \multirow{3}{*}{ Sample } & \multirow{3}{*}{$\begin{array}{c}\text { The time } \\
\text { of EA } \\
\text { addition }\end{array}$} & \multirow{3}{*}{$\begin{array}{l}\text { Monomer } \\
\text { /Dimer }\end{array}$} & \multicolumn{6}{|c|}{ Diad concentration } \\
\hline & & & \multicolumn{3}{|c|}{ Method $1^{\mathrm{a}}$} & \multicolumn{3}{|c|}{ Method $2^{b}$} \\
\hline & & & $\mathrm{P}_{2}(\mathrm{EA}-\mathrm{EA})$ & $\mathrm{P}_{2}(\mathrm{EA}-\mathrm{BMA})$ & $\mathrm{P}_{2}(\mathrm{BMA}-\mathrm{BMA})$ & $P_{2}(E A-F A)$ & $\mathrm{P}_{2}(\mathrm{EA}-\mathrm{BMA})$ & $\mathrm{P}_{2}(\mathrm{BMA}-\mathrm{BMA})$ \\
\hline A & 0 & 9.9 & 0.25 & 0.50 & 0.25 & 0.26 & 0.48 & 0.26 \\
\hline B & 5 & 6.7 & 0.30 & 0.40 & 0.30 & 0.29 & 0.42 & 0.29 \\
\hline $\mathrm{C}$ & 10 & 5.5 & 0.32 & 0.36 & 0.32 & 0.32 & 0.36 & 0.32 \\
\hline D & 20 & 5.1 & 0.33 & 0.34 & 0.33 & 0.33 & 0.34 & 0.33 \\
\hline
\end{tabular}

a Using the ratio of EA monomer to dimer.

b Using the ratio of EA-EA to EA-BMA dimer.

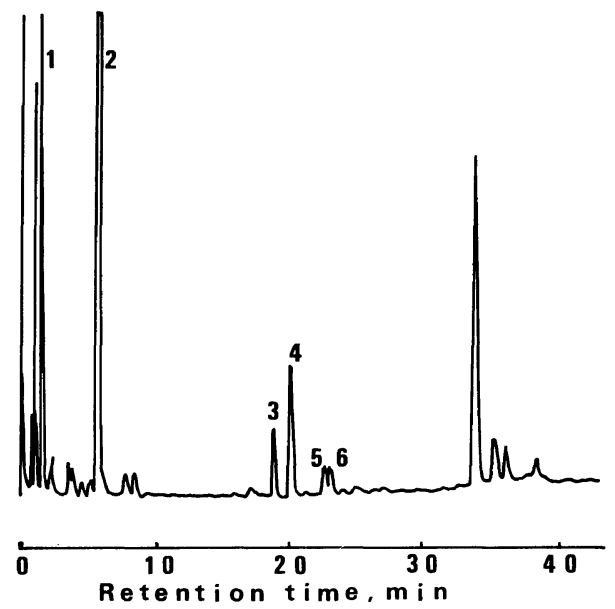

Figure 3. Typical pyrogram of EA-BMA copolymer (EA/BMA mole ratio $=8: 2$ ); Peaks 1 , EA; 2, BMA; 3, EA-EA dimer (1) $\mathrm{CH}_{2}-\mathrm{CH}_{2}-\mathrm{CH}_{2} ; 4$, EA-EA $\mathrm{COOC}_{2} \mathrm{H}_{5} \mathrm{COOC}_{2} \mathrm{H}_{5}$

dimer (2) $\mathrm{CH}_{2}=\mathrm{C}-\mathrm{CH}_{2}-\mathrm{CH}_{2}$, EA-BMA dimer (1) $\mathrm{CH}_{2}-\mathrm{CH}_{2}-\stackrel{\mathrm{CH}}{\mathrm{CH}_{3}}$<smiles>C=C(CCCCC(=O)OCC)C(=O)OCC</smiles>

lymerization, the samples which have different sequence distributions of monomer units can be obtained by changing the duration of EA addition. Table II shows the analytical results of diad concentrations. As the duration of EA addition becomes longer, the concentration $\mathrm{P}_{2}(\mathrm{EA}-\mathrm{EA})$ becames larg-

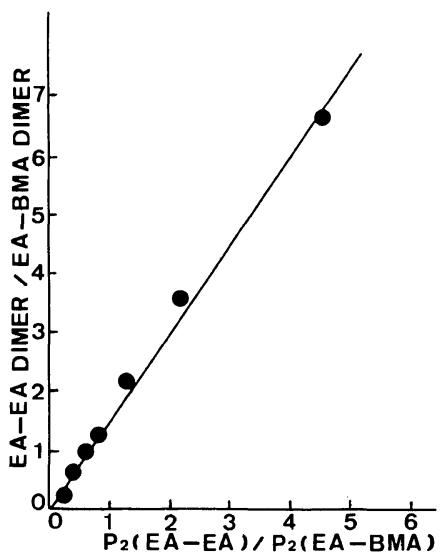

Figure 4. Relationship between the peak area ratio of EA-EA dimer/EA-BMA dimer in pyrolytic products and the diad concentration ratio of $\mathrm{P}_{2}(\mathrm{EA}-\mathrm{EA}) / \mathrm{P}_{2}(\mathrm{EA}-$ BMA).

er, and the results from Methods 1 and 2 show in good agreement. Thus, we conclude that the sequence distributions can be evaluated by using the acrylate monomer/ dimer ratio.

\section{Application to Sequence Distributions of EA-} BA-BMA Terpolymers

The sequence distributions of EA-BABMA terpolymers which were synthesized in different ways, were comparatively evaluated using the acrylate monomer/dimer ratio. The polymerization was carried out to obtain the terpolymers with the EA/BA/BMA ratio of $3 / 3 / 4$ (mole ratio), in two different 
Pyrolysis Gas Chromatographic Evaluation

Table III. Results of pyrolytic analysis

\begin{tabular}{|c|c|c|c|c|c|c|}
\hline \multirow{2}{*}{ Sample } & \multirow{2}{*}{$\begin{array}{l}\text { The time of } \\
\text { BA addition } \\
\text { min }\end{array}$} & \multicolumn{3}{|c|}{$\begin{array}{c}\text { Analytical } \\
\text { composition }^{\mathrm{a}}\end{array}$} & \multicolumn{2}{|c|}{ Monomer/Dimer ${ }^{\mathrm{b}}$} \\
\hline & & EA & BA & BMA & EA & BA \\
\hline A & 0 & 28.1 & 31.7 & 40.2 & 5.3 & 4.9 \\
\hline B & 15 & 28.1 & 29.4 & 42.5 & 6.1 & 3.6 \\
\hline
\end{tabular}

a The composition (mole ratio) calculated by pyrolysis analysis proposed in the previous paper.

b Peak area ratios in the pyrogram.

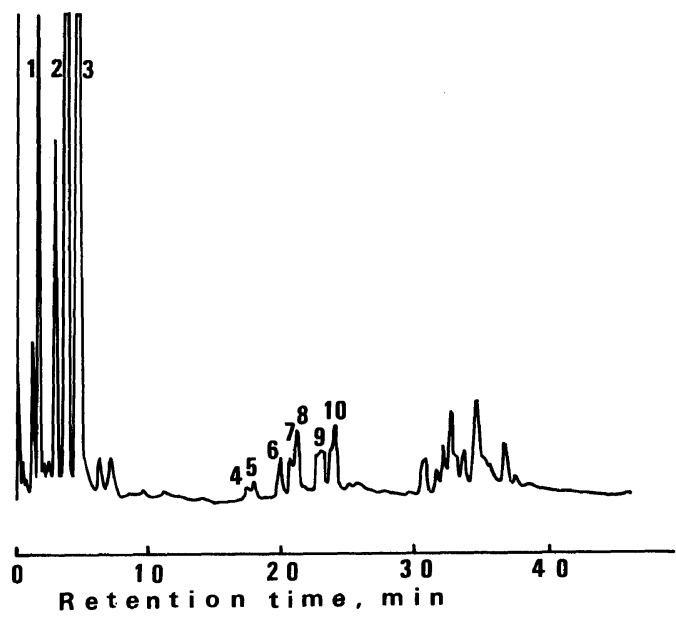

Figure 5. Typical pyrogram of EA-EA-BMA terpolymer: Peak 1, EA; 2, BA; 3, BMA; 4, EA-EA dimer (1); 5, EA-EA dimer (2); 6, EA-BMA dimer (1)+(2); 7, EA-BA dimer (1); 8, EA-BA dimer (2); 9, BA-BMA dimer $(1)+(2)$; 10, BA-BA dimer $(1)+(2)$.

ways: i.e., addition of the initiator solution to the monomer mixture of EA, BA and BMA (Sample A); and addition of the initiator plus BA monomer solution to the monomer mixture of EA and BMA (Sample B).

Figure 5 shows the pyrogram of EA-BABMA terpolymer, including peaks for EA-EA, BA-BA dimer and EA-BA hybrid dimer as acrylic dimers. Table III shows the analytical compositions of the samples by the use of the peak area ratio of monomer to dimer for EA and BA cited in the same table. To calculate the ratio of monomer to dimer, the EA-BA hybrid dimer peak area in the pyrogram was divided by considering the rel-
Table IV. Ratio of diad concentrations evaluated using acrylate monomer/dimer ratio

\begin{tabular}{ccc}
\hline Sample & $\begin{array}{c}{\left[\mathrm{P}_{2}(\text { EA-EA) }\right.} \\
+\mathrm{P}_{2}(\text { EA-BA) }\end{array}$ & $\begin{array}{c}{\left[\mathrm{P}_{2}(\mathrm{BA}-\mathrm{BA})\right.} \\
\left.+\mathrm{P}_{2}(\mathrm{EA}-\mathrm{BA})\right]\end{array}$ \\
& $/ \mathrm{P}_{2}$ (EA-BMA) & $\mathrm{P}_{2}(\mathrm{BA}-\mathrm{BMA})$ \\
\hline $\mathrm{A}$ & 1.0 & 1.0 \\
$\mathrm{~B}$ & 0.9 & 1.5 \\
\hline
\end{tabular}

ative sensitibity for FID detector of EA and BA, and added to the EA-EA and BA-BA dimer peak areas, respectively. The analytical compositions obtained by the former method proposed in the previous paper ${ }^{5}$ were in good agreement with those of samples. Therefore it may be said that the monomer/dimer ratios for $\mathrm{EA}$ and $\mathrm{BA}$ indicate the sequence distributions of samples.

The diad content ratio of $\mathrm{P}_{2}$ (acrylateacrylate) to $P_{2}$ (acrylate-methacrylate) could be estimated from the same relation for the ratio of monomer to dimer as shown in Figure 2. In cases of EA-BA-BMA terpolymers, the diad ratios of EA: $\left[\mathrm{P}_{2}(\mathrm{EA}-\mathrm{EA})+\mathrm{P}(\mathrm{EA}-\mathrm{BA})\right]$ to $\mathrm{P}_{2}(\mathrm{EA}-\mathrm{BMA})$ and that of $\mathrm{BA}:\left[\mathrm{P}_{2}(\mathrm{BA}-\right.$ $\left.\mathrm{BA})+\mathrm{P}_{2}(\mathrm{BA}-\mathrm{EA})\right] / \mathrm{P}_{2}(\mathrm{BA}-\mathrm{BMA})$ should be estimated with these relationships. The observed values of the samples are shown in Table IV.

Considering the polymerization processes, the content of $\mathrm{P}_{2}(\mathrm{BA}-\mathrm{BA})$ would be larger and that of $\mathrm{P}_{2}$ (BA-BMA) smaller in sample $\mathrm{B}$. The results obtained using monomer/dimer ratio agree with this prediction. Table $\mathrm{V}$ shows the observed percentages for individual dimer 
Table V. Percentage of pyrolytic dimer products

\begin{tabular}{cccccc}
\hline & & \multicolumn{3}{c}{ Pyrolytic dimer product } \\
\cline { 4 - 5 } Sample & & \multicolumn{2}{c}{$\%$} & \\
& EA-EA & EA-BMA & EA-BA & BA-BMA & BA-BA \\
\cline { 2 - 5 } & 7.4 & 14.0 & 30.2 & 25.5 & 22.9 \\
B & 7.0 & 12.9 & 28.1 & 21.7 & 30.3 \\
\hline
\end{tabular}

${ }^{a}$ Calculated by the dimer peak area observed in the pyrogram.

products in the total area of peaks. Although these values do not agree with the diad content from the standpoint of boundary effects, in comparison of Sample B with A, the content of the BA-BMA dimer decreases and that of BA-BA dimer increases remarkably. These differences also support the estimation made by use of the monomer/dimer ratio (see Table IV).

Acknowledgements. We thank Dr. S. Tsuge of the Department of Synthetic Chemistry, Faculty of Engineering, Nagoya University for his helpful suggestions and observations.

\section{REFERENCES}

1. S. Tsuge, Y. Sugimura, and T. Nagaya, J. Anal. Appl. Pyrolysis, 1, 221 (1980).

2. H. Ohtani, T. Nagaya, Y. Sugimura, and S. Tsuge, $J$. Anal. Appl. Pyrolysis, 4 (1982).

3. T. Shimono, M. Tanaka, and T. Shono, J. Anal. Appl. Pyrolysis, 1, 77 (1979).

4. J. K. Haken and T. R. McKay, J. Chromatogr., 80, 75 (1973).

5. S. Yamaguchi and S. Yokoyama, Bunseki Kagaku, 33, 153 (1984).

6. Y. Mori, A. Ueda, H. Tanzawa, K. Matsuzaki, and H. Kobayashi, Macromol. Chem., 176, 699 (1975).

7. H. McCormic, J. Chromatgr., 40, 1 (1963).

8. T. Otsu and B. Yamada, "Kyojugo," Vol. 1, The Society of Polymer Science, Japan, Ed., Baifukan Co., Tokyo, 1975. 